\title{
SWCNT-Based Biosensor Modelling for pH Detection
}

\author{
Mohammad Javad Kiani, ${ }^{1,2}$ M. A. A. Razak, ${ }^{1}$ F. K. Che Harun, ${ }^{1}$ \\ M. T. Ahmadi, ${ }^{3}$ and Meisam Rahmani ${ }^{1}$ \\ ${ }^{1}$ Faculty of Electrical Engineering, Universiti Teknologi Malaysia, 81310 Skudai, Johor, Malaysia \\ ${ }^{2}$ Department of Electrical Engineering, Islamic Azad University, Yasooj Branch, Yasooj, Iran \\ ${ }^{3}$ Department of Electrical Engineering, Urmia University, Urmia, Iran \\ Correspondence should be addressed to F. K. Che Harun; fauzan@fke.utm.my
}

Received 16 October 2014; Accepted 5 January 2015

Academic Editor: Stefan I. Voicu

Copyright (C) 2015 Mohammad Javad Kiani et al. This is an open access article distributed under the Creative Commons Attribution License, which permits unrestricted use, distribution, and reproduction in any medium, provided the original work is properly cited.

Different forms of CNT delivery have been discovered with several biomedical functions during past decades. The mechanisms of the cellular uptake of CNTs are mainly maintained due to the chemical nature, the cell type, and the features of the molecules, which are used to functionalize the nanotube exterior. Since single-wall carbon Nanotube (SWCNT) has unique chemical and physical properties, it is a great applicant for $\mathrm{pH}$ sensing. In addition, ion sensitive FET (ISFET) base on nanostructured SWCNT have covered a new method to help genetic investigators restructure metabolic pathways in cells, recognize the progression of disease, and expand diagnostics and therapeutics. Particularly, because PH sensing is very crucial for the constancy of enzymes, it is essential to extend the cost efficient types of this sensing. In this research, the conductance changes of the CNT-based ISFET device with different $\mathrm{pH}$ values can be modelled by ion concentration of the solution. In addition, the electrical current of channel is imagined as a function of $\mathrm{pH}$ levels, which can be controlled by a control factor $(\alpha)$. Thus, ISFET based nanostructured SWCNT is proposed focusing on the area of electrical detection of hydrogen ions of the electrolyte membrane. Besides, electrical detection of hydrogen ion applications is suggested to be used by modelling the delivery of SWCNT sheets. In the end, after comparing the proposed model and experimental data, it has been reported that there is a good compatibility between them.

\section{Introduction}

Carbon nanotubes (CNTs) can be imagined as a sheet of carbon atoms turned up into a pipe with a diameter of nanometres [1-3]. There are two major types of CNTs including single-walled carbon nanotubes (SWCNTs) and multiwalled carbon nanotubes (MWCNTs). SWCNTs are made from numerous concentric layers of turned graphene as shown in Figure 1. SWCNTs are particularly described by a high feature proportion [4]. Furthermore, their multipurpose physicochemical features facilitate the noncovalent and covalent beginning of several biosensing and biomedicine functions of appropriate entities [5].

Therefore, the development of their distinctive thermal, optical, electrical, and spectroscopic properties in a biological framework is expected to bring about great progress in the treatment of disease and the discovery of biomolecules such as antigen-antibody, cells, DNA, and other biomolecules [6].
Principally, SWCNTs can be used to avoid dispersing proteins of CNTs without destroying or damaging the nanotube construction. In general, physical entrapment or adsorption can help to gather the proteins [7]. Enhanced solvability of CNTs in organic or aqueous flushes is a main factor in biological functions [7]. Many researchers attempted to investigate useful approaches in which CNTs are functionally connected to biomolecules as identifying factors [8]. In general, this process can take place by covalent functionalization and noncovalent approach [9]. For instance, in carbon nanotube-based ISFET, the conductance of the CN-based ISFET is dependent on $\mathrm{pH}$ changes to $\mathrm{pH}[10]$. Similarly, diarylethenes can be considered as a bridge that is able to conversely change nonconjugated conditions to conjugated conditions. The molecular bridge can have two functions, transporting electrical current and sensing/identification through biological occurrences such as DNA hybridization and protein/substrate binding [6]. 


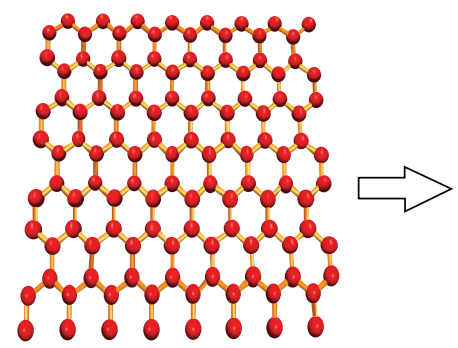

Graphene sheet
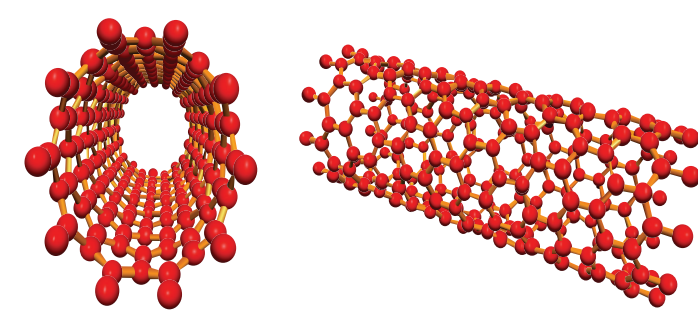

SWCNT made from a wrapped graphene sheet

FIGURE 1: Wrapping of graphene sheet to form SWCNT.

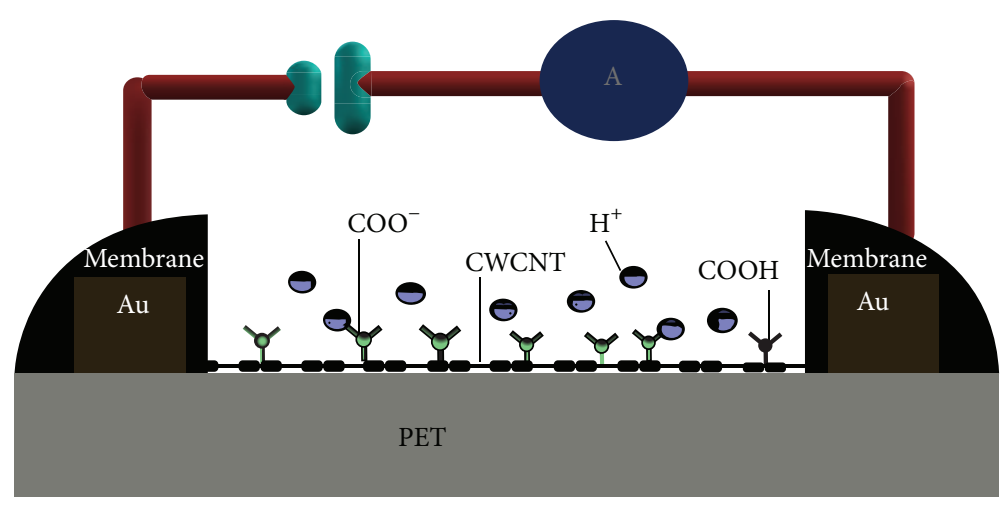

FIGURE 2: SWCNT-based ISFET structure for $\mathrm{pH}$ sensing.

\section{Structure and Detection Mechanism of SWCNT-Based pH Sensor}

The homogeneous and transferable SWCNT-based bendable ISFET sensor is an adaptable biological and chemical sensor, which creates in vivo functional capable device due to the biocompatible characteristic of polymer substrate [11]. The assemblage of nanomaterials on cut-price, clear, and bendable substrate via layer-by-layer ( $\mathrm{LbL}$ ) bottom-up structure is useful and proposes a new concept of industrialized procedure [12]. As demonstrated in the proposed structure (Figure 2), the dissolved $\mathrm{Cr}-\mathrm{Au}$ films were used as electrical contacts on the top of the nanotubes and a certain amount of CNT is deposited into the sensor.

In fact, when $\pi$ electrons in one-dimensional CNTs are transferred on the surfaces, the transporters move on the surface of the device [13]. Consequently, the ecological perturbations occurring in the areas surrounding carbon surfaces have a strapping impact on the conductance of CNTs.

In the current paper, the interaction between CNTs and solution with different $\mathrm{pH}$ causes considerable alterations in conductance of nanotube network field-effect transistors (NTNFET) device by electrostatic gating method [14]. In the previous studies, the proposed recognition methods of carbon-based materials were electrostatic gating, transporter mobility modifying, and Schottky obstruction results [1518]. Electrostatic gating which is influenced by adsorbed charge type has been approved to describe the conductance amend of carbon nanotube transistors [19]. In contrast, the conductivity of the NTNFET tools has an effect on increasing the number of transporters in the channel. The similarity of CNTs with different hydrogen ion concentrations is due to nucleic acid base $\pi$ stacking on the nanotube surface. It causes the hydrophilic molecular part indicating the exterior and a steady hybrid with individual CNTs to be shaped by covering around the bonds through the fragrant interfaces between CNTs sidewalls and nucleotide bases $[20,21]$. In the present paper, the model of ISFET tools is planned as detectors of $\mathrm{pH}$ sensing. The suggested model imitates the behaviour of ISFET tool to differentiate between wild-type (wt) and mutant (mut) alleles [22]. Different $\mathrm{pH}$ rates, as a function of entrance voltage, are replicated using $\mathrm{pH}$-sensing factor. In the end, a study has been reported evaluating/comparing the offered model and experimental data in [10].

\section{3. $I-V$ Characteristic of Perfectly Symmetric SWCNT}

The $I-V$ characteristic model of CNT has been begun with the modelling of single layer graphene band structure. By Taylor series the energy distribution relation near the Fermi point can be obtained as [23]

$$
E(k)= \pm \frac{t 3 a_{\mathrm{C}-\mathrm{C}}}{2} \sqrt{\left(\frac{2}{3 d}\right)^{2}+k_{x}^{2}}
$$

where $a_{\mathrm{C}-\mathrm{C}}=1.42 \AA$ is carbon-carbon $(\mathrm{C}-\mathrm{C})$ bond length, $t=2.7(\mathrm{eV})$ is the nearest neighbour $\mathrm{C}-\mathrm{C}$ tight binding 
overlap energy, $d$ is the diameter of the CNT, and the $( \pm)$ signals are connected to the conductance and valence bands. It can be deduced that the first band gap energy can be written as $E_{G}=2 a_{\mathrm{C}-\mathrm{C}} t / d=(0.8 \mathrm{eV}) / d(\mathrm{~nm})$. Additionally, due to the parabolic band structure near the $k=0$ points, in the presence of Taylor expansion, the band energy is modified as

$$
E \approx \frac{E_{G}}{2}+\frac{\hbar^{2} k_{x}^{2}}{2 m^{*}}
$$

where $m^{*}$ is the effective mass for CNT that depends on the diameter of the tube, $\hbar$ is the concentrated Plank constant, and $k_{x}$ is wave vector component lengthways of the nanotubes, which can be obtained in the parabolic part of the band energy:

$$
k_{x}=\sqrt{\frac{4 E}{3 a_{\mathrm{C}-\mathrm{C}} t}-\frac{8}{9 d^{2}}} .
$$

Since the subbands position has a strapping impact on the number of modes, $M(E)$, at a given level of energy, the parabolic estimate of the band diagram can be employed when the connected energy consists of the under the conductance band. In other words, the mode concentration $M(E)$ improves with energy [23]. Taking the spin degeneracy into consideration, the number of conduction channels can be described as

$$
M(E)=2 \frac{\Delta E}{\Delta k \cdot L}=\frac{3 a_{\mathrm{C}-\mathrm{C}} t}{L}\left(\frac{4 E}{3 a_{\mathrm{C}-\mathrm{C}} t}-\frac{8}{9 d^{2}}\right)^{1 / 2},
$$

where $L$ is the channel length. The conductance influenced by large channels, which make it capable of subsequent ohmic scaling law rooted in Landauer method, is regarded because of two aspects. The first aspect is the interface resistance which is autonomous of the length and the second one is related to the fact that the relation of conductance and the width is nonlinear and depends on the number of the modes in the conductor materials, so we can write [24]

$$
G=\frac{2 q^{2}}{h} \int_{-\infty}^{+\infty} d E M(E) T(E)\left(-\frac{d f}{d E}\right),
$$

where $q$ is electron charge, $h$ is Plank constant, and $T$ is the transmission probability of an introduced electron throughout the canal which is estimated to $(T(E)=1)$ in the ballistic channels [25]. Because of the fact that the term of $d f / d E$ is significant only near the Fermi energy the number of definite modes at the Fermi energy is two [12]. Plugging (4) into (5) and in terms of the Fermi-Dirac distribution function, conductance can be voluntarily gained as a function of the length of nanoribbon which has a noticeable impact on conductivity [26]:

$$
\begin{aligned}
G= & \frac{2 q^{2}}{h} \frac{3 a_{\mathrm{C}-\mathrm{C}} t}{L}\left(\frac{4}{3 a_{\mathrm{C}-\mathrm{C}} t}\right)^{1 / 2} \\
& \cdot \int_{-\infty}^{+\infty}\left(E-\frac{2 a_{\mathrm{C}-\mathrm{C}} t}{3 d^{2}}\right)^{1 / 2} d\left(-\frac{1}{1+e^{\left(E-E_{F}\right) / K_{B} T}}\right) .
\end{aligned}
$$

Replacing the boundary of integral as follows, SWCNT conductance model is modified as

$$
\begin{aligned}
G= & \frac{4 q^{2}}{h L}\left(3 a_{\mathrm{C}-\mathrm{C}} t \pi k_{B} T\right)^{1 / 2} \\
& \cdot\left[\int_{0}^{+\infty}{\frac{x}{\left(1 /\left(1+e^{x-\eta}\right)\right)}}^{-1 / 2} d x\right. \\
& \left.+\int_{0}^{+\infty}{\frac{x}{\left(1 /\left(1+e^{x+\eta}\right)\right)}}^{-1 / 2} d x\right]
\end{aligned}
$$

where $x=\left(E-E_{g}\right) / k_{B} T$ and the normalized Fermi energy is $\eta=\left(E_{F}-E_{g}\right) / k_{B} T$. This equation can mathematically be resolved by utilizing the partial integration technique. The Fermi-Dirac distribution function has diverse shapes in degenerate and nondegenerate conditions which are qualified by $(\eta \gg 0)$ and $(\eta \ll 0)$, respectively $[27,28]$. In the nondegenerate limit, there are few electrons in the conductance band and the boundary of the transmission group is far over the Fermi energy evaluated to $K_{B} T$, so the Fermi-Dirac integral can be estimated by Maxwell-Boltzmann distribution aspect of $\eta(E)=\exp (\eta)$. In degenerate condition, conversely, the concentration of electrons in the density of state and the Fermi energy reclines inside the conductance band and Fermi-Dirac function can be estimated as $\eta(E)=1$. Therefore, the overall conductance model of carbon nanotubebased $\mathrm{pH}$ biosensor can be gained comparably to that of silicon described by Gunlycke et al. [29]:

$$
G=\frac{4 q^{2}}{h L}\left(3 a_{\mathrm{C}-\mathrm{C}} t \pi k_{B} T\right)^{1 / 2}\left[\mathscr{I}_{-1 / 2}(\eta)+\mathscr{I}_{-1 / 2}(-\eta)\right]
$$

where $\mathscr{I}_{-1 / 2}(\eta)$ is the Fermi-Dirac integral of order $(-1 / 2)$. Consistent with the current-voltage characteristic of SWCNT-based ISFET structure, the presentation of $\mathrm{pH}$ sensor can be accessed through this equation [30]. The channel area has the features of the resistor in small voltage between drain $\left(V_{\mathrm{DS}}\right)$ and source assuming that the source and substrate terminals are supposed in ground potential. Furthermore, the relationship between channel current and conductance can be substituted by common conductance model of SWCNT

$$
\begin{aligned}
I_{d}= & \frac{3 q^{2}\left(3 \pi a^{3} t^{3} k_{B} T\right)^{1 / 2}}{h L} \\
& \cdot\left[\mathscr{I}_{-1 / 2}(\eta)+\mathscr{I}_{-1 / 2}(-\eta)\right]\left(V_{g s}-V_{t}\right) .
\end{aligned}
$$

As it is shown in Figure 3, the presentation of $\mathrm{pH}$ sensor base on SWCNT nanostructured is assessed by the current-voltage curve. Buffer solution $\mathrm{pH} 7$ was inserted in the chamber to calculate the current of channel (i.e., drain current $I_{d}$ versus gate voltage) before the $\mathrm{pH}$ value of electrolyte membrane has been added [31].

There is a positive relationship between planned model for $\mathrm{pH}$ sensor based SWCNT and experimental result which is reported from [31]. 


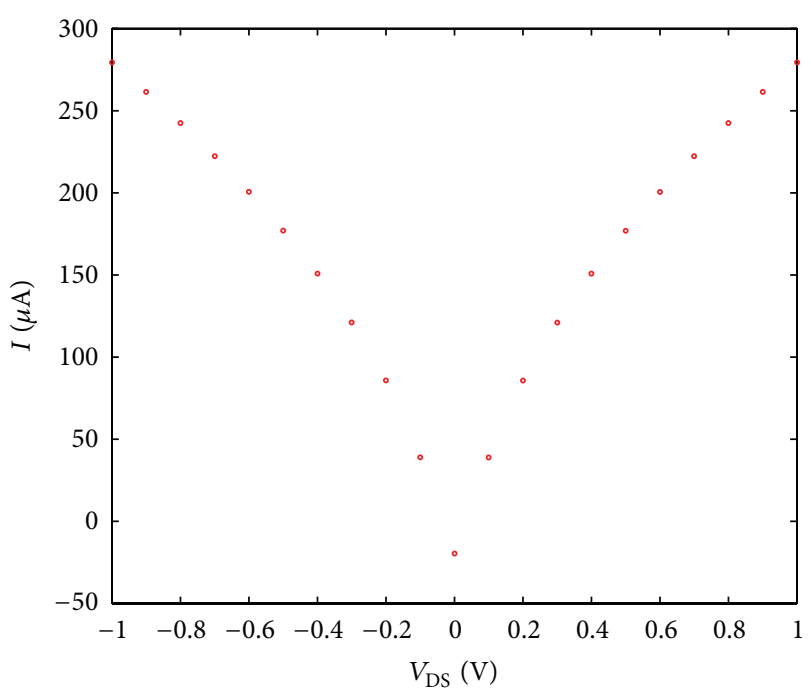

(a)

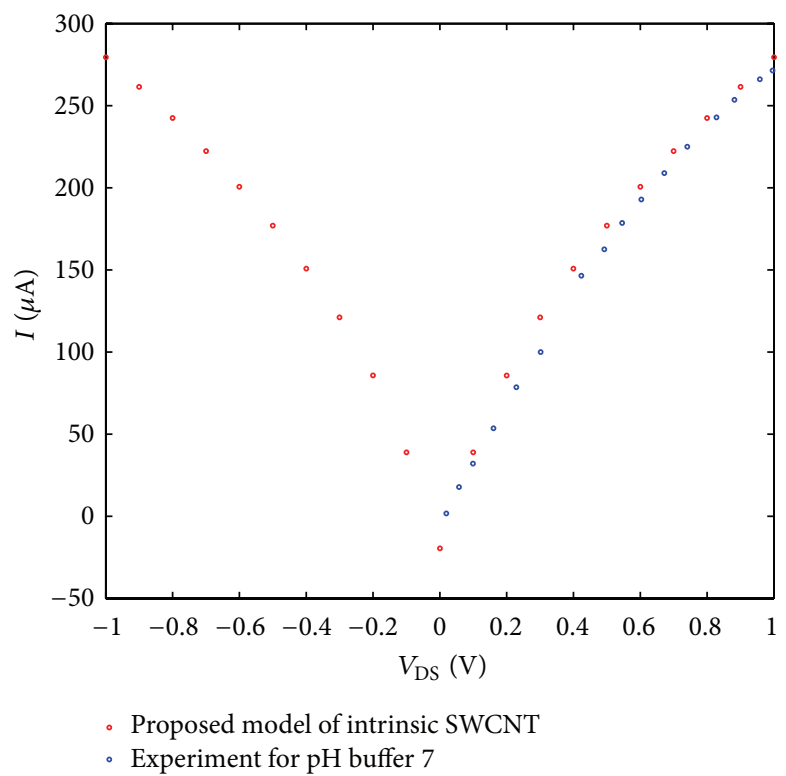

(b)

FIgURE 3: (a) $I-V$ characteristic model of SWCNT. (b) Comparison between carbon nanotube current models with experimental data [10] for buffer solution $\mathrm{pH} 7$.

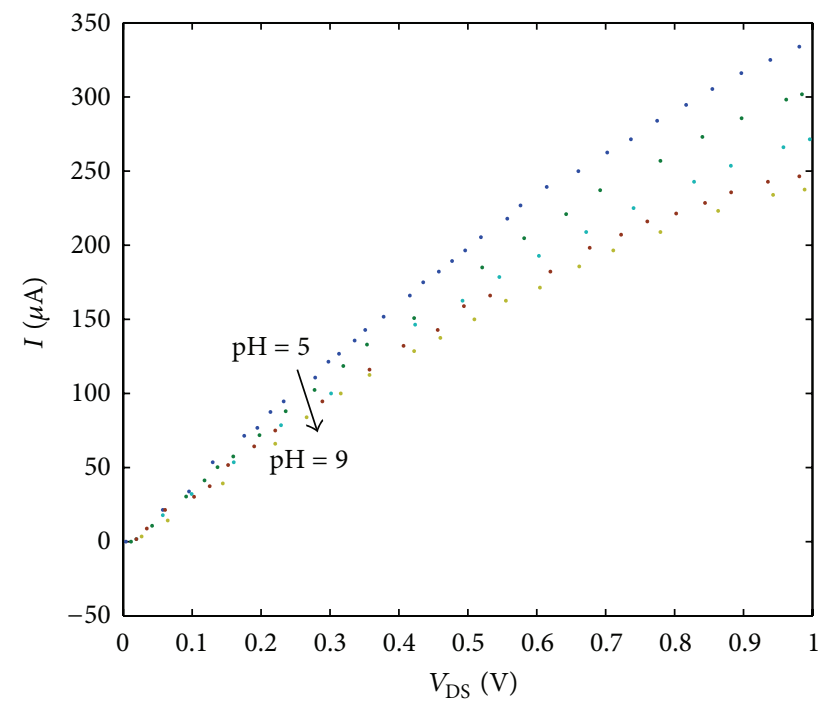

FIGURE 4: The comparison between SWCNT current model and extracted experimental data [10] for different $\mathrm{pH}$ value from $\mathrm{pH} 5$ to $\mathrm{pH} 9$ which shows considerable changes in current of SWCNTbased sensor for different $\mathrm{pH}$ buffer.

\section{Proposed Model for SWCNT-Based ISFET}

Different rates of $\mathrm{pH}$ buffer have been inserted in the chamber to permit attachment to SWCNT surfaces to be saturated. As it is represented in Figure 4, by affecting the gate voltage in the electrolyte membrane, it is obviously declared that the conductance of FET-based CNT demonstrates different behaviour and after that the $I-V$ feature of ISFET tool will be converted. The different layers of CNT have been observed by considering the current versus the voltage, which is recognized from transferring characteristic curve.

Altogether, $V_{g}$ can be recognized as a good sign of $\mathrm{pH}$ sensing. As it is shown in Figure 4, when the rates of $\mathrm{pH}$ decline from 9 to 5 , more $\mathrm{H}^{+}$ions are adsorbed and the sensor will be able to attract more molecules in the same method used to modify the $V_{g}$ on the tool. In light of this fact, the current paper has focused on showing a new model for $\mathrm{pH}$ sensor. In this model, the $\mathrm{pH}$ buffer as a function of gate voltage is replicated and $\mathrm{pH}$ aspect $(\propto)$ is recommended. Consequently, in order to get a superior insight into the role of $\mathrm{pH}$ buffer, ISFET modelling is utilized to gain a significant concept for $I-V$ characteristic of SWCNT-based sensor. To achieve this purpose, two electrodes of sensor, as it is demonstrated in Figure 2, are deemed as source and drain contacts. Finally, gate voltage is modelled by $\mathrm{pH}$ (following); in other words, $V_{g}$ is supposed as a function of $\mathrm{pH}\left(V_{g s} \sim \mathrm{pH}\right)$ :

$$
\begin{aligned}
& V_{g s} \text { (with electrolyte gate) } \\
& =\frac{\alpha}{\mathrm{pH}} V_{g s} \text { (without electrolyte gate), }
\end{aligned}
$$

where $\mathrm{pH}$ sensing feature $(\propto)$ is proposed and $\mathrm{pH}$ is the diverse rate of $\mathrm{pH}$ buffer. In the nanosaturation area, $\mathrm{pH}$ model is utilized as a function of gate voltage and the currentvoltage relation for the $n$-channel MOSFET is personalized as

$$
\begin{aligned}
I_{d}= & \frac{3 q^{2}\left(3 \pi a^{3} t^{3} k_{B} T\right)^{1 / 2}}{h L}\left[\mathscr{I}_{-1 / 2}(\eta)+\mathscr{I}_{-1 / 2}(-\eta)\right] \\
& \cdot\left(\frac{\propto}{p H} V_{g s(\text { without electrolyte gate) }}-V_{t}\right) .
\end{aligned}
$$




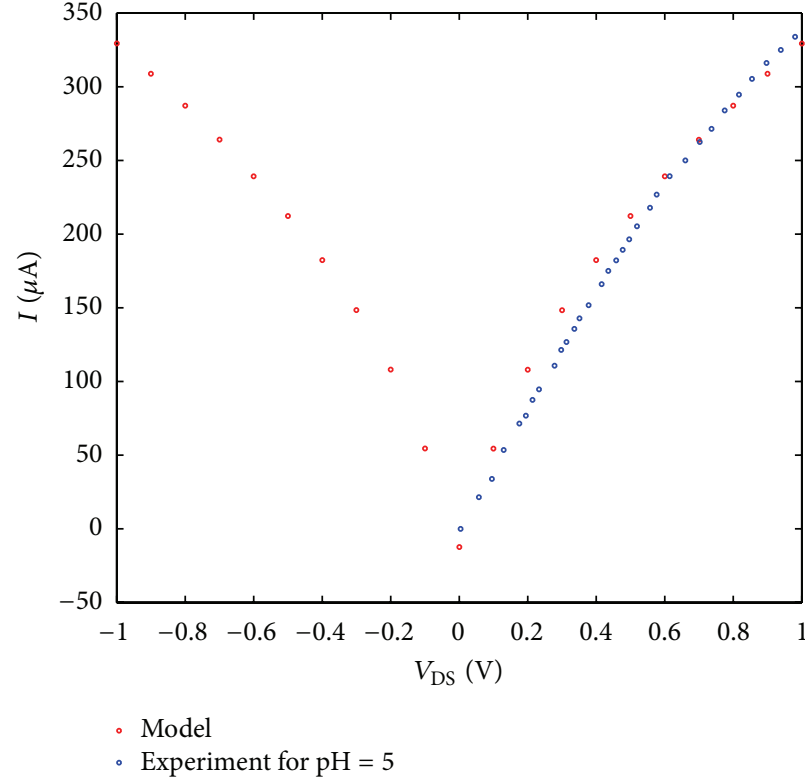

(a)

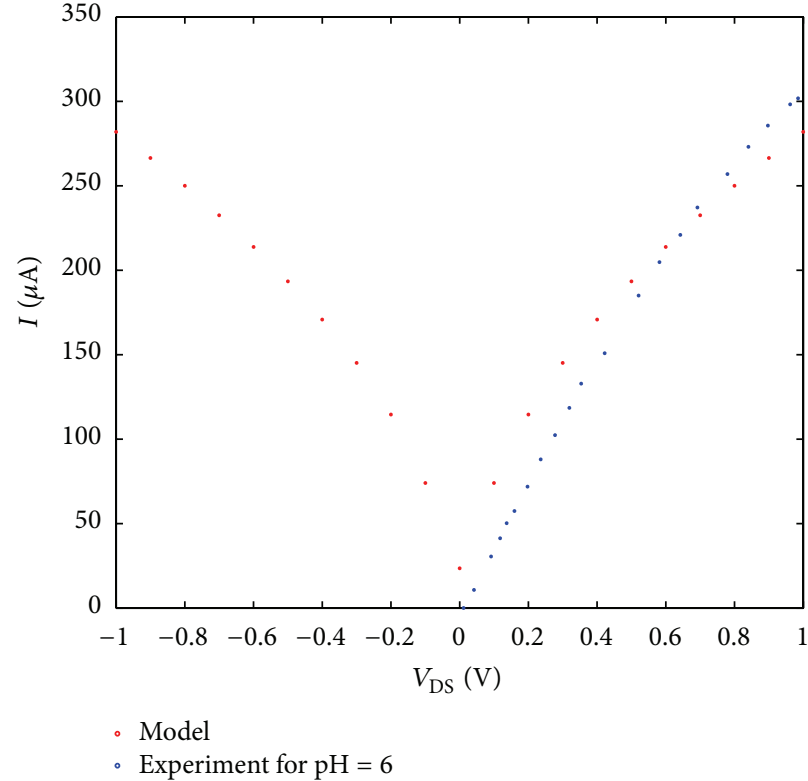

(b)

FIGURE 5: Current versus drain voltage curves for both the proposed model and the experimental data [10] after adding the solution with $\mathrm{pH}$ 5 and $\mathrm{pH} 6$, respectively.

The shape of $(\mathrm{pH})$ parameter offers different rates of $\mathrm{pH}$ buffer. Therefore, the hydrogen ion concentration adsorbed on SWCNT surface by iteration method is modelled as

$$
\alpha=\alpha_{1} e^{-\alpha_{2} \cdot \mathrm{pH}} .
$$

From experiment data [10], $\left(\alpha_{1}\right.$ and $\left.\alpha_{2}\right)$ parameters are estimated where $\alpha_{1}=364.41$ and $\alpha_{2}=0.088$. Ultimately, consistent with the planned model of $\mathrm{pH}$ sensor by means of nanostructured nanotube, the current-voltage changes can be customized as

$$
\begin{aligned}
I_{d}= & \frac{3 q^{2}\left(3 \pi a^{3} t^{3} k_{B} T\right)^{1 / 2}}{h L}\left[\mathscr{I}_{-1 / 2}(\eta)+\mathscr{I}_{-1 / 2}(-\eta)\right] \\
& \cdot\left(\frac{\alpha_{1} e^{-\alpha_{2} \cdot \mathrm{pH}}}{\mathrm{pH}} V_{g s(\text { without electrolyte gate) }}-V_{t}\right) .
\end{aligned}
$$

Each diagram in Figures 5 and 6 shows definite $\mathrm{pH}$ buffer of electrolyte membrane.

For instance, when $\mathrm{pH}$ buffer improves from 5 to 7 , it is remarkable that the model is closer to the blue line and the conductance of nanotube will be reduced about $35 \mu \mathrm{s}$; in the same way we can evaluate other experimental data as well. It is actually shown that $I-V$ characteristic curve can be managed by altering $\mathrm{pH}$ buffer through the $\mathrm{pH}$ feature. In addition, the planned model is powerfully estimated with experimental data [10].

According to Figure 6, the quantity of conductance will be saturated by rising the $\mathrm{pH}$ buffer from 8 to 9 , probably holding the fact that the concentration of hydrogen ions is inadequate and the sensor transfer cure has been saturated. According to what is discussed above, one could strongly assert that the current versus gate voltage of SWCNT-based ISFET device with different $\mathrm{pH}$ values can be displayed by ion concentration of the solution. In addition, the current of its channel is assumed as a function of $\mathrm{PH}$ levels, which can be controlled by a control parameter $(\alpha)$. The number of carriers changing in the channel influences the conductance of the CNT-based FET devices. FET-based CNT with high sensitivity was applied to detect the $\mathrm{pH}$ changes, based on the conductance variations. The performance of CNTbased biosensor for $\mathrm{pH}=5$ to $\mathrm{pH}=9$ is evaluated and the analytical results of the proposed model for $\mathrm{pH}$ sensor with appropriate parameters are compared with the experimental which indicates a good agreement. It is evident in the figures that the points calculated and obtained from our model agreeably overlap the measurement data.

\section{Conclusion}

Carbon nanotubes (CNTs) with considerable electrochemical properties as the leading materials in nanotechnology have attracted scientific attention. Due to its considerable features, single-walled CNT (SWCNT) can be employed as an electrochemical sensor. The rising potentials of nanostructured SWCNT-based ISFET in elevated responsive and useful emergence of single-base polymorphism as the key to the identification of genetic diseases and understanding of modified medicine can be confirmed. The PH sensing mechanism plays an important role in several aspects affecting the structure and activity of enzymes. As a $\mathrm{pH}$ sensor, $\mathrm{pH}$ buffer can present the gate voltage. In the current study, the gate voltage is presumed as a function of $\mathrm{pH}$ buffer of electrolyte membrane, which exemplifies $\mathrm{pH}$-sensing factor. 


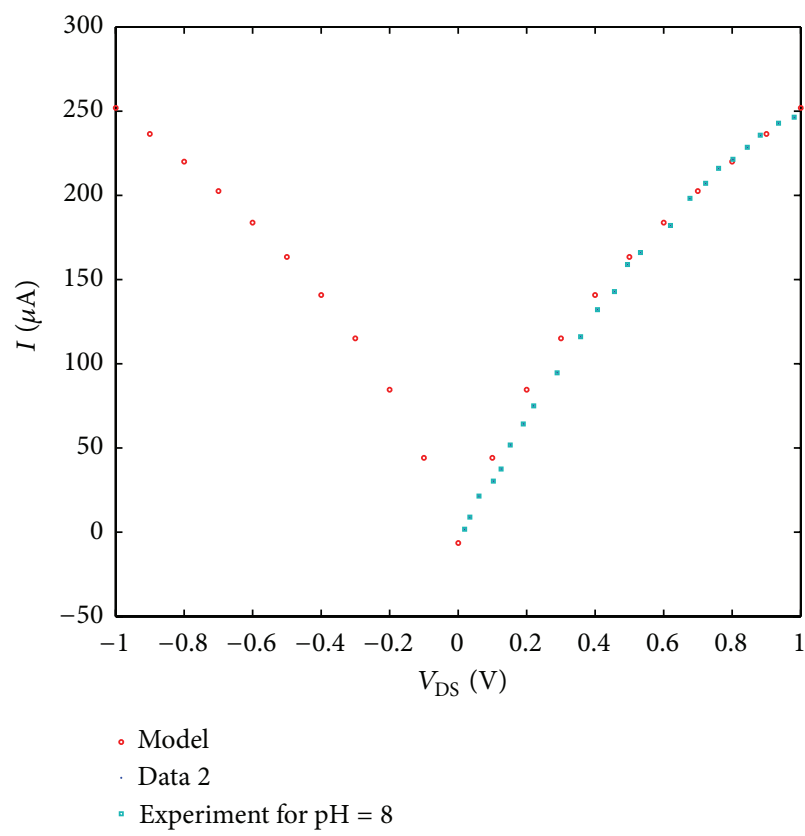

(a)

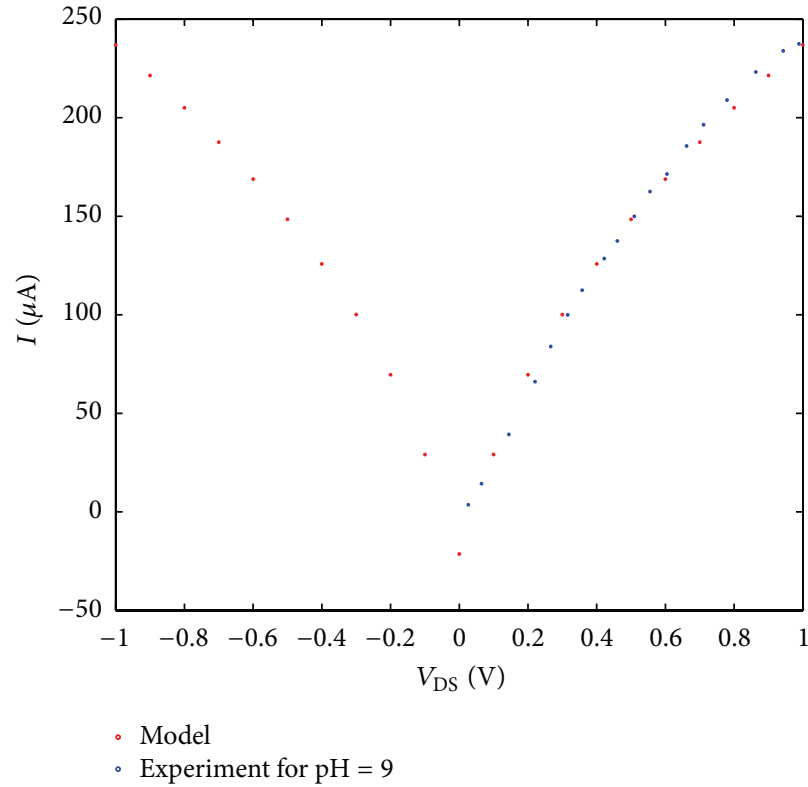

(b)

FIGURE 6: $G-V_{\mathrm{DS}}$ characteristic of CNT proposed model with experimental data [10] for solution with $\mathrm{pH} 8$ and $\mathrm{pH} 9$.

Measurements demonstrate that the conductance of SWCNT is considerably reduced when the $\mathrm{pH}$ buffer improves. As a $\mathrm{pH}$ sensor, the gate voltage can be displayed by ion concentration of different $\mathrm{pH}$ buffer, which demonstrates that $\mathrm{pH}$ sensing aspect presented model verifies the reported experimental data as well.

\section{Conflict of Interests}

The authors declare that there is no conflict of interests regarding the publication of this paper.

\section{Acknowledgments}

The authors would like to acknowledge the financial support from the Research University Grant of the Ministry of Higher Education (MOHE), Malaysia. Also thanks are due to the Research Management Center (RMC) of Universiti Teknologi Malaysia (UTM) for providing excellent research environment in which to complete this work.

\section{References}

[1] J. M. Tan, G. Karthivashan, P. Arulselvan, S. Fakurazi, and M. Z. Hussein, "Sustained release and cytotoxicity evaluation of carbon nanotube-mediated drug delivery system for betulinic acid," Journal of Nanomaterials, vol. 2014, Article ID 862148, 11 pages, 2014.

[2] Y. Luo, X. Li, J. Zhang, C. Liao, and X. Li, “The carbon nanotube fibers for optoelectric conversion and energy storage," Journal of Nanomaterials, vol. 2014, Article ID 580256, 13 pages, 2014.

[3] J. M. Tan, G. Karthivashan, P. Arulselvan, S. Fakurazi, and M. Z. Hussein, "Characterization and in vitro sustained release of silibinin from $\mathrm{pH}$ responsive carbon nanotube-based drug delivery system," Journal of Nanomaterials, vol. 2014, Article ID 439873, 10 pages, 2014.

[4] M. S. P. Shaffer and A. H. Windle, "Fabrication and characterization of carbon nanotube/poly (vinyl alcohol) composites," Advanced Materials, vol. 11, no. 11, pp. 937-941, 1999.

[5] R. H. Baughman, A. A. Zakhidov, and W. A. de Heer, "Carbon nanotubes - the route toward applications," Science, vol. 297, no. 5582, pp. 787-792, 2002.

[6] X. Tang, S. Bansaruntip, N. Nakayama, E. Yenilmez, Y.-I. Chang, and Q. Wang, "Carbon nanotube DNA sensor and sensing mechanism," Nano Letters, vol. 6, no. 8, pp. 1632-1636, 2006.

[7] R. Saito, G. Dresselhaus, and M. S. Dresselhaus, Physical Properties of Carbon Nanotubes, vol. 4, World Scientific, 1998.

[8] M. Shim, N. W. S. Kam, R. J. Chen, Y. Li, and H. Dai, "Functionalization of carbon nanotubes for biocompatibility and biomolecular recognition," Nano Letters, vol. 2, no. 4, pp. 285288, 2002.

[9] C. B. Jacobs, M. J. Peairs, and B. J. Venton, "Review: carbon nanotube based electrochemical sensors for biomolecules," Analytica Chimica Acta, vol. 662, no. 2, pp. 105-127, 2010.

[10] D. Lee and T. Cui, "Low-cost, transparent, and flexible singlewalled carbon nanotube nanocomposite based ion-sensitive field-effect transistors for $\mathrm{pH} /$ glucose sensing," Biosensors and Bioelectronics, vol. 25, no. 10, pp. 2259-2264, 2010.

[11] G. Massobrio, P. Massobrio, and S. Martinoia, "Modeling the neuron-carbon nanotube-ISFET junction to investigate the electrophysiological neuronal activity," Nano Letters, vol. 8, no. 12, pp. 4433-4440, 2008.

[12] S. W. Lee, B.-S. Kim, S. Chen, Y. Shao-Horn, and P. T. Hammond, "Layer-by-layer assembly of all carbon nanotube ultrathin films for electrochemical applications," Journal of the American Chemical Society, vol. 131, no. 2, pp. 671-679, 2009. 
[13] D. Fu and L.-J. Li, "Label-free electrical detection of DNA hybridization using carbon nanotubes and graphene," Nano Reviews, vol. 1, article 5354, 2010.

[14] I. Heller, A. M. Janssens, J. Männik, E. D. Minot, S. G. Lemay, and C. Dekker, "Identifying the mechanism of biosensing with carbon nanotube transistors," Nano Letters, vol. 8, no. 2, pp. 591595, 2008.

[15] M. J. Kiani, M. T. Ahmadi, H. Karimi Feiz Abadi, M. Rahmani, A. Hashim, and F. K. Che Harun, "Analytical modelling of monolayer graphene-based ion-sensitive FET to $\mathrm{pH}$ changes," Nanoscale Research Letters, vol. 8, no. 1, p. 173, 2013.

[16] M. J. Kiani, F. K. C. Harun, S. N. Hedayat, E. Akbari, S. M. Mousavi, and M. T. Ahmadi, "Carrier motion effect on bilayer graphene nanoribbon base biosensor model," Journal of Computational and Theoretical Nanoscience, vol. 10, no. 6, pp. 1338-1342, 2013.

[17] M. J. Kiani, F. K. C. Harun, M. Saeidmanesh, M. Rahmani, A. Parvizi, and M. T. Ahmadi, "Perpendicular electric field effect on electronic properties of bilayer graphene," Science of Advanced Materials, vol. 5, no. 12, pp. 1954-1959, 2013.

[18] M. J. Kiani, M. T. Ahmadi, S. A. Ravangard, M. Saeidmanesh, M. Ghadiry, and F. K. C. Harun, "Layer effect on graphene nanoribbon quantum capacitance," Journal of Computational and Theoretical Nanoscience, vol. 10, no. 10, pp. 2328-2331, 2013.

[19] I. Heller, S. Chatoor, J. Männik, M. A. G. Zevenbergen, C. Dekker, and S. G. Lemay, "Influence of electrolyte composition on liquid-gated carbon nanotube and graphene transistors," Journal of the American Chemical Society, vol. 132, no. 48, pp. 17149-17156, 2010.

[20] R. A. MacDonald, B. F. Laurenzi, G. Viswanathan, P. M. Ajayan, and J. P. Stegemann, "Collagen-carbon nanotube composite materials as scaffolds in tissue engineering," Journal of Biomedical Materials Research Part A, vol. 74, no. 3, pp. 489-496, 2005.

[21] P. Hu, J. Zhang, L. Li, Z. Wang, W. O'Neill, and P. Estrela, "Carbon nanostructure-based field-effect transistors for labelfree chemical/biological sensors," Sensors, vol. 10, no. 5, pp. 5133-5159, 2010.

[22] A. Star, E. Tu, J. Niemann, J.-C. P. Gabriel, C. S. Joiner, and C. Valcke, "Label-free detection of DNA hybridization using carbon nanotube network field-effect transistors," Proceedings of the National Academy of Sciences of the United States of America, vol. 103, no. 4, pp. 921-926, 2006.

[23] M. T. Ahmadi, Z. Johari, N. A. Amin, S. M. Mousavi, and R. Ismail, "Carbon nanotube conductance model in parabolic band structure," in Proceedings of the IEEE International Conference on Semiconductor Electronics (ICSE '10), pp. 256-259, IEEE, June 2010.

[24] M. T. Ahmadi, Z. Johari, N. A. Amin, A. H. Fallahpour, and R. Ismail, "Graphene nanoribbon conductance model in parabolic band structure," Journal of Nanomaterials, vol. 2010, Article ID 753738, 4 pages, 2010.

[25] S. Datta, Electronic Transport in Mesoscopic Systems, Cambridge University Press, Cambridge, UK, 2002.

[26] N. Peres, A. H. C. Neto, and F. Guinea, "Conductance quantization in mesoscopic graphene," Physical Review B, vol. 73, no. 19, Article ID 195411, 8 pages, 2006.

[27] R. B. Dingle and R. Dingle, Asymptotic Expansions: Their Derivation and Interpretation, Academic Press, London, UK, 1973.

[28] M. T. Ahmadi, Z. Johari, D. C. Y. Chek, N. A. Amin, and R. Ismail, "Modelling of graphene nanoribbon Fermi energy,"
Journal of Nanomaterials, vol. 2010, Article ID 909347, 6 pages, 2010.

[29] D. Gunlycke, D. A. Areshkin, and C. T. White, "Semiconducting graphene nanostrips with edge disorder," Applied Physics Letters, vol. 90, no. 14, Article ID 142104, 2007.

[30] M. Passlack, "III-V metal-oxide-semiconductor technology," in Proceedings of the IEEE 20th International Conference on Indium Phosphide and Related Materials (IPRM '08), p. 1, Versailles, France, 2008.

[31] X. Dong, Y. Shi, W. Huang, P. Chen, and L.-J. Li, "Electrical detection of DNA hybridization with single-base specificity using transistors based on CVD-grown graphene sheets," Advanced Materials, vol. 22, no. 14, pp. 1649-1653, 2010. 

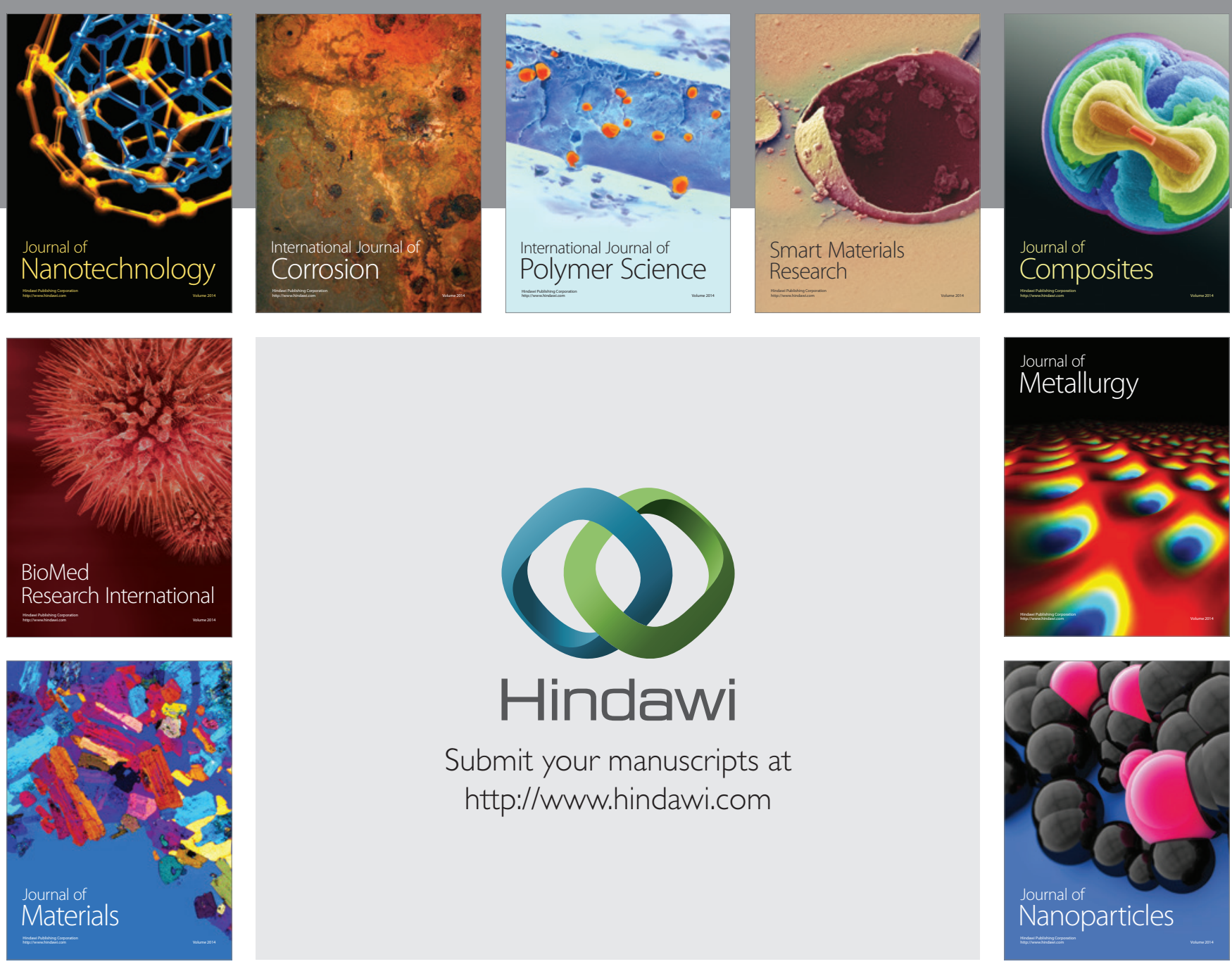

Submit your manuscripts at http://www.hindawi.com
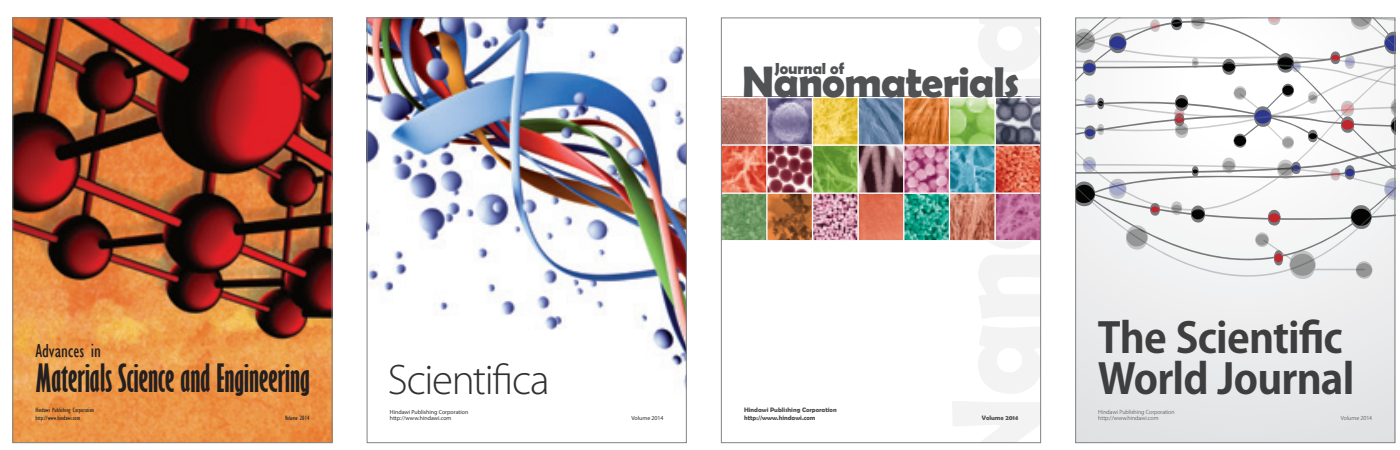

\section{The Scientific World Journal}
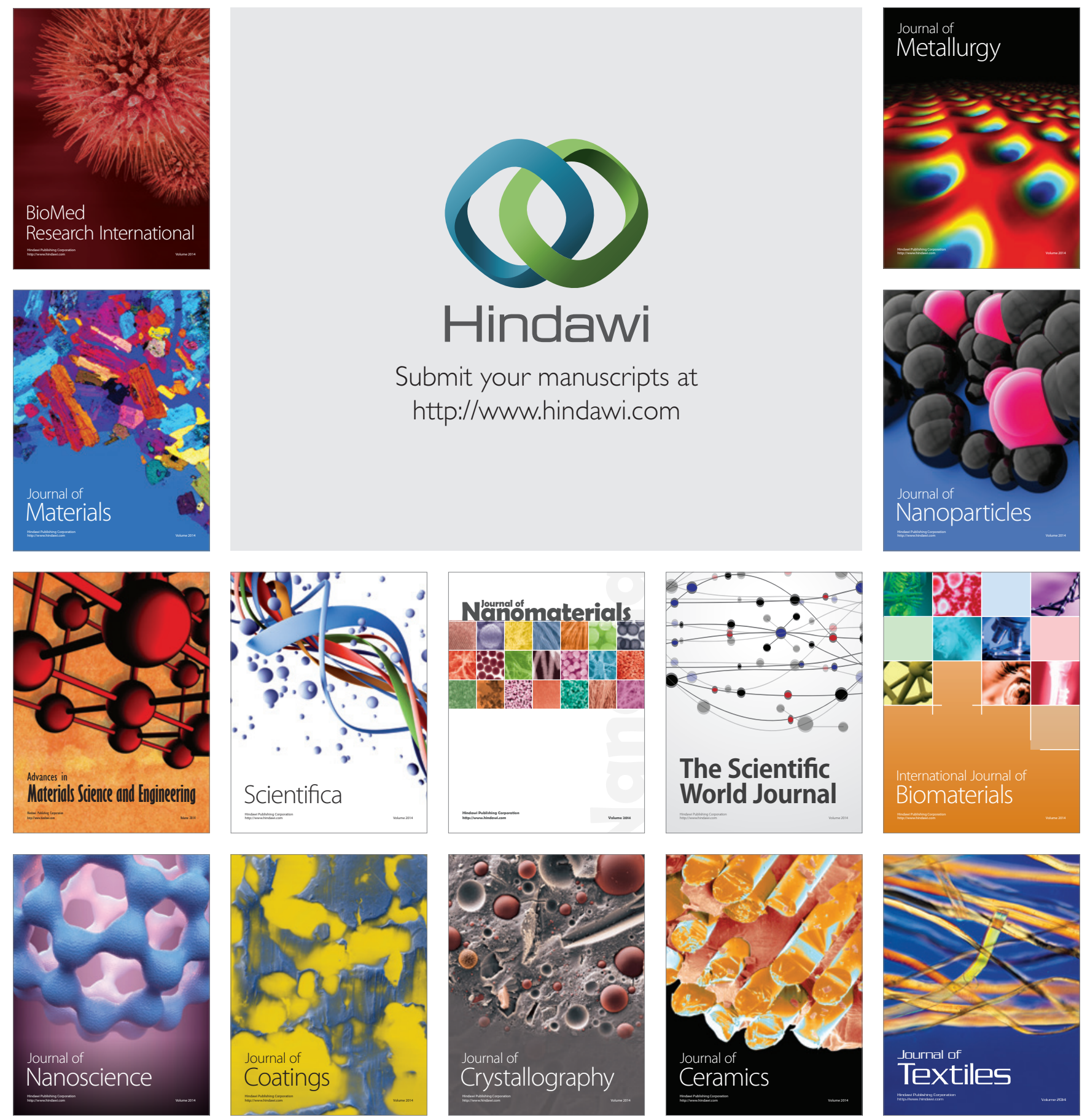